\title{
Cigarette Smoking and Its Hazards in Kidney Transplantation
}

\author{
Muhammad Abdul Mabood Khalil, ${ }^{1}$ Jackson Tan, ${ }^{2}$ Said Khamis, ${ }^{1}$ \\ Muhammad AshhadUllah Khalil, ${ }^{3}$ Rabeea Azmat, ${ }^{4}$ and Arslan Rahat Ullah ${ }^{5}$ \\ ${ }^{1}$ Diaverum Prince Abdul Majeed Renal Centre, Al Imam Ahmad Ibn Hanbal, Jeddah 21146, Saudi Arabia \\ ${ }^{2}$ RIPAS Hospital, Bandar Seri Begawan BA1710, Brunei Darussalam \\ ${ }^{3}$ Khyber Teaching Hospital, Peshawar, Khyber Pakhtunkhwa 25000, Pakistan \\ ${ }^{4}$ Aga Khan University Hospital, Karachi 74800, Pakistan \\ ${ }^{5}$ Northwest General Hospital \& Research Centre, Peshawar, Khyber Pakhtunkhwa 2500, Pakistan \\ Correspondence should be addressed to Muhammad Abdul Mabood Khalil; doctorkhalil1975@hotmail.com
}

Received 2 April 2017; Accepted 22 June 2017; Published 27 July 2017

Academic Editor: Joanna Domagala-Kulawik

Copyright (C) 2017 Muhammad Abdul Mabood Khalil et al. This is an open access article distributed under the Creative Commons Attribution License, which permits unrestricted use, distribution, and reproduction in any medium, provided the original work is properly cited.

\begin{abstract}
Cigarette smoking affects many organs. It causes vasoconstriction through activation of sympathetic nervous system which leads to elevation of blood pressure and reduction in glomerular filtration rate and filtration pressure. It also causes thickening of renal arterioles. Cigarette smoking increases the risk of microalbuminuria and accelerates progression of microalbuminuria to macroalbuminuria. Furthermore, it causes rapid loss of glomerular filtration rate in chronic kidney disease patients. After kidney donation, these factors may be injurious to the solitary kidney. Kidney donors with history of cigarette smoking are prone to develop perioperative complications, pneumonia, and wound infection. Postkidney transplantation various stressors including warm and cold ischemia time, delayed graft function, and exposure to calcineurin inhibitors may result in poor graft function. Continuation of cigarette smoking in kidney transplant recipients will add further risk. In this review, we will specifically discuss the effects of cigarette smoking on normal kidneys, live kidney donors, and kidney transplant recipients. This will include adverse effects of cigarette smoking on graft and patient survival, cardiovascular events, rejection, infections, and cancers in kidney transplant recipients. Lastly, the impact of kidney transplantation on behavior and smoking cessation will also be discussed.
\end{abstract}

\section{Introduction}

Cigarette smoking is common worldwide, despite the numerous deterrent measures that have been put in place over the decades. The number of smokers reported in 2015 was 1.1 billion [1]. Worldwide, tobacco use causes nearly 6 million deaths per year, and current trends show that tobacco use will cause more than 8 million deaths annually by 2030 [2]. On average, smokers die 10 years earlier than nonsmokers [3]. The association of cigarette smoking with cardiovascular diseases, chronic obstructive pulmonary disease, and cancers is well known. Cigarette smoking increases the risk of coronary heart disease and stroke by 2-4 times and that of lung cancer by 25 times [4]. Cigarette smoking also causes chronic obstructive pulmonary disease (COPD) and smokers are 12 to 13 times more likely to die from COPD than nonsmokers [4]. The present review focuses on adverse effects of smoking in normal kidneys, kidney donors, and kidney transplant recipient and effect of kidney transplantation on smoking cessation.

\section{Effect of Cigarette Smoking on Kidney}

Cigarette smoking can cause acute and chronic effects $[5,6]$. Acutely, cigarette smoking increases sympathetic nervous system activity resulting in tachycardia and high blood pressure. Increased sympathetic nervous system activity causes increased catecholamine activity in the circulation. This causes vasoconstriction in the vascular system [7]. Vascular resistance in renovascular bed increases by 11\% [7]. This reduces glomerular filtration rate by $15 \%$ and filtration fraction by $18 \%$. The chronic effects of cigarette smoking on kidney are less clear. There is evidence that renal plasma flow decreases in chronic smokers and this is accompanied by 


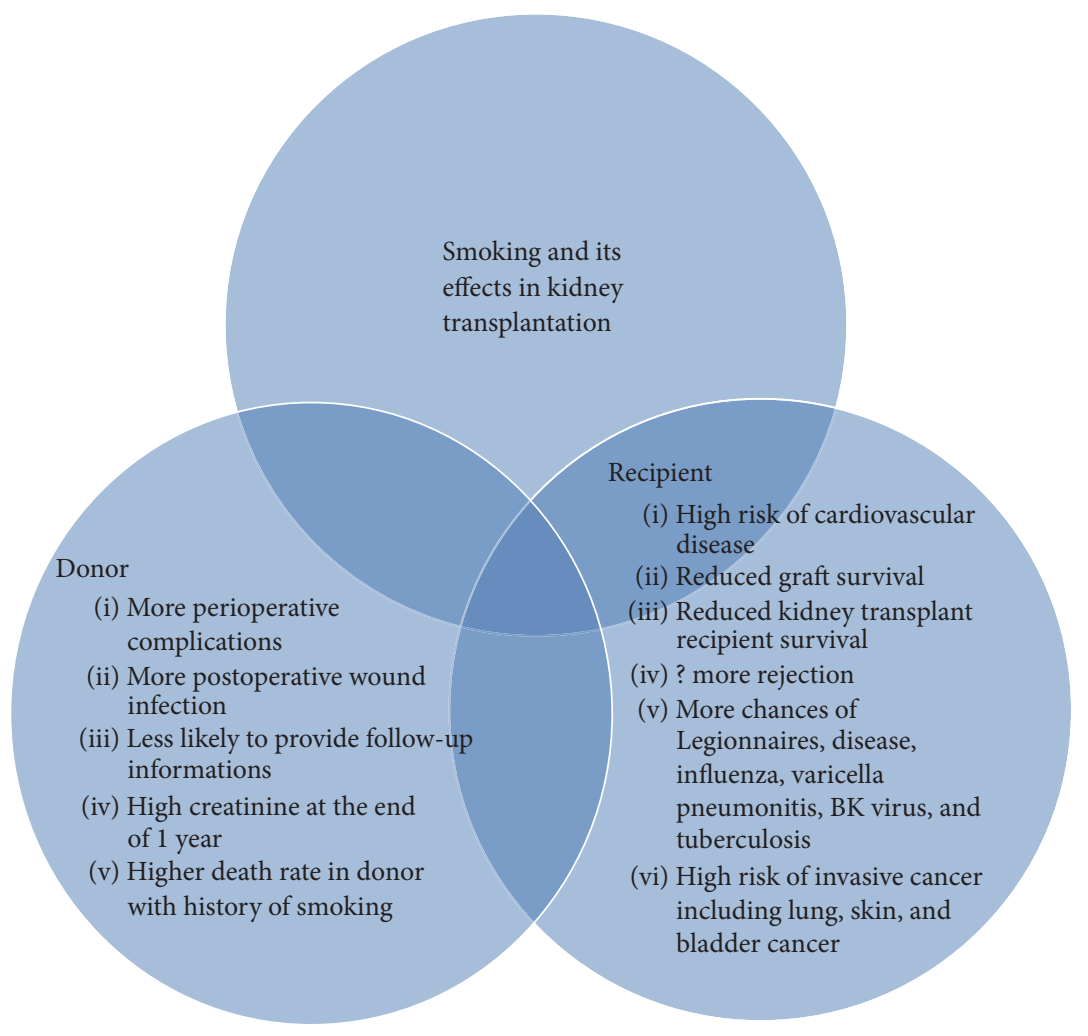

FIGURE 1: Smoking and its effects in kidney transplantation.

modest elevation of endothelin. Endothelin through vasoconstriction will induce functional abnormalities. Cigarette smoking has been associated with thickening of renal and myocardial arterioles $[8,9]$ and has been shown to be an independent predictor of proteinuria $[10,11]$. The effect of cigarette smoking in diabetic kidneys has been documented in various studies. Cigarette smoking increases the risk of microalbuminuria in smokers [12]. It also causes rapid progression of microalbuminuria to macroalbuminuria [13] and causes rapid loss of glomerular filtration rate (GFR) leading to rapid progression of diabetic nephropathy [14]. Beside diabetic kidney disease, cigarette smoking has been implicated in nondiabetic kidney diseases. Various studies have shown progression of nondiabetic chronic kidney diseases due to cigarette smoking $[15,16]$. Cigarette smoking is deleterious after kidney transplantation. Figure 1 shows cigarette smoking and its effects in both kidney donors and recipient.

\section{Cigarette Smoking and Kidney Donors}

Kidney donors undergo general anesthesia for donor nephrectomy and are prone to develop complications in the perioperative period. Cigarette smoking causes increased bronchial secretion and impaired mucociliary clearance. It also results in increased carboxyhemoglobin and secondary polycythemia. Stopping cigarette smoking for only 12 hours can greatly reduce carboxyhemoglobin concentrations, improve oxygen content and availability, and reverse negative inotropic and arrhythmic effects $[17,18]$. Smokers' polycythemia and blood viscosity reverses within few days while sputum production declines over a period of 6 weeks after smoking cessation [19]. Pneumonia is the third most common infection after urinary tract and wound infection in kidney donors [20]. Smokers have a higher risk of pulmonary and wound infections after surgery than nonsmokers [21]. Based on this data, the Amsterdam Forum Guidelines recommends cessation of cigarette smoking 6 weeks before kidney donation [22].

There is plenty of available data on kidney transplant recipients implicating cigarette smoking in patient and graft survival. However, there is paucity of work on the effects cigarette smoking on kidney donors. A recent study by Segev's and his colleagues through a multivariate analysis adjusting for age, gender, race, systolic BP, and history of hypertension revealed a significantly higher death rate among kidney donors who were smokers [23]. Cigarette smoking in kidney donors is associated with higher rate of perioperative complications [24] and postoperative wound infections [25]. These donors are less likely to provide follow-up information requested by transplant centers [26]. There are mixed results for impact on graft function. Robert et al. found that cigarette smoking in cadaveric kidney donor may be associated with delayed graft function on univariate analysis [27]. But after adjusting for correlated outcome data and controlling for other potential prognostic factors, this relationship became insignificant. In a retrospective analysis by Heldt et al., kidney donors who actively smoke or have a past history of tobacco use were found to have higher serum creatinine at end of 1 year as compared to nonsmokers [28]. Similarly, recipients of 
TABLE 1: Summary of previous publications on implication of cigarette smoking in kidney donors.

\begin{tabular}{|c|c|c|c|}
\hline Number & Author & Journal/year & Conclusion \\
\hline (1) & Segev et al. [23] & JAMA/2010 & Higher death rate in kidney donors with cigarette smoking \\
\hline (2) & Patel et al. [24] & Transplantation/2008 & More perioperative complications \\
\hline (3) & Mjøen et al. [25] & Transplantation/2009 & More postoperative wound infections \\
\hline$(4)$ & Ommen et al. [26] & Am J Transplant/2011 & $\begin{array}{l}\text { Less likely to provide follow-up information requested by } \\
\text { transplant centers }\end{array}$ \\
\hline$(5)$ & Robert et al. [27] & J Crit Care/2010 & No impact on delayed graft function \\
\hline (6) & Heldt et al. [28] & AdvUrol/2011 & $\begin{array}{l}\text { (1) Active smoker or past history of smoking has high creatinine } \\
\text { at end of } 1 \text { year as compared to the nonsmoker. } \\
\text { (2) Recipients had higher creatinine and lower GFR }\end{array}$ \\
\hline (7) & $\begin{array}{l}\text { Underwood et al. } \\
\qquad[29]\end{array}$ & Clin Transplant/2014 & $\begin{array}{l}\text { (1) No difference in postoperative complications } \\
\text { (2) No effect on graft survival } \\
\text { (3) Reduced recipient survival if donor was a smoker }\end{array}$ \\
\hline (8) & Keles et al. [30] & Transplant Proc/2015 & $\begin{array}{l}\text { Significant drop in cigarette smoking from } 47 \% \text { to } 29 \% \text { after } \\
\text { kidney donation }\end{array}$ \\
\hline
\end{tabular}

kidneys from smokers had higher creatinine and lower GFR [28]. However, Jha et al. found no difference in postoperative complications and graft survival between the two groups [3]. Interestingly though, donor cigarette smoking reduced recipient survival [29].

For live kidney donors, transplantation provides an opportunity to quit cigarette smoking. Keles et al. reported significant drop in cigarette smoking from $47 \%$ to $29 \%$ after kidney donation [30]. Therefore, kidney donors with history of cigarette smoking should be referred to smoking cessation clinics. More studies are needed to compare the impact of cigarette smoking in kidney donors on donor and recipient survival and graft outcomes. Table 1 shows summary of various studies done in kidney donors.

\section{Cigarette Smoking and Kidney Recipient}

It is well established that cigarette smoking causes chronic obstructive airway disease, coronary artery disease, and cancer [4]. Cigarette smoking is also associated with increased mortality and graft loss in kidney transplant recipients [31]. In this section, we will review the implications of cigarette smoking on cardiovascular disease, mortality, graft survival, rejection, infections, and cancer in kidney transplant recipients.

4.1. Cigarette Smoking and Cardiovascular Diseases in Kidney Transplant Recipient. Cardiovascular disease is the leading cause of death in kidney transplant recipients. Patients usually die with a well-functioning graft due to cardiovascular events. Cigarette smoking can lead to poorer survival of the transplanted kidney, partly due to its role in atherosclerosis, endothelial dysfunction, and vascular disease [32]. Kidney transplant recipients who smoke have a relative risk of 1.9 of having coronary artery disease as reported by Kasiske et al. [33]. Shorter survival has been reported in various studies due to cardiovascular diseases and cigarette smoking has been implicated as one of the contributing factors [34, 35]. Ponticelli et al. reported that cigarette smoking was associated with a higher risk of cardiovascular diseases [36]. The risk of cardiovascular diseases increases with the increasing pack-years of smoking per year. The relative risk for major cardiovascular disease events with cigarette smoking 11 to 25 pack-years at transplant was 1.56 , whereas that of cigarette smoking for more than 25 pack-years was 2.14 [37]. Kidney transplant recipients who smoke have higher prevalence of diabetes, hypertension, and dyslipidemia which would predispose them to a higher risk of cardiovascular deaths [38].

In summary, cigarette smokers, therefore, have more cardiovascular events. The risk goes up with increasing number of pack-years. Kidney transplant recipients have more prevalence of other atherogenic risk factors including diabetes, hypertension, and dyslipidemia. Smoking in combination with these risk factors put kidney transplant recipients at risk of more cardiovascular events.

4.2. Cigarette Smoking and Graft Survival. Cigarette smoking causes increased sympathetic nervous system activity $[5,6]$, increases renal arterioles thickness $[8,9]$, worsens proteinuria $[10,11]$, and causes rapid loss of glomerular filtration rate in chronic kidney disease [12]. We expect cigarette smoking to cause the same effects in transplanted kidney too. In addition, transplanted kidney undergoes various stressors including warm ischemia, cold ischemia, and delayed graft function and, later on, rejection and exposure to calcineurin inhibitors. Not surprisingly, all these factors may add up and affect long-term graft survival. There is plenty of evidence available that smoking reduces graft survival [33, 34, 39, $40,42,44,45]$. Various studies have reported relative risk of $1.30-2.3[32,42-44]$ and hazard ratio of 1.74 to 3.3 for graft loss [29, 39]. Remote past smoking may have little impact on graft survival [39]. It has been shown that quitting cigarette smoking for more than 5 year before transplantation reduce the relative risk of graft failure by $34 \%$ [33]. Therefore, smoking cessation advice should be given to all chronic kidney disease patients waiting for transplant to make sure that they stop smoking well ahead of their surgery. Heavy cigarette smoking has been shown to be associated with 
higher risk of graft failure compared to moderate smoking. Kasiske and Klinger reported that cigarette smoking of more than 25 pack-years at transplantation (compared to cigarette smoking less than 25 pack-years or never having smoked) was associated with a $30 \%$ higher risk of graft failure [37]. The effect of cigarette smoking may not be evident earlier on and may appear later. Gombos et al. did not find any difference in serum creatinine at 3 months, but creatinine at 1 year was significantly higher in smokers [40]. Sung et al. reported that pretransplant cigarette smoking had kidney graft survival of $84 \%, 65 \%$, and $48 \%$ at 1,5 , and 10 years, respectively [41], compared with graft survival in nonsmokers of $88 \%, 78 \%$, and $62 \%(P=0.007)$. One may argue that graft loss may be due to death with a functional graft due to smoking. However, death-censored graft survival was also adversely affected by pretransplant smoking in recipients of both cadaveric $(P=0.02)$ and living donor kidneys $(P=0.02)$ [41]. Smoking related chronic obstructive airway disease is common in transplant recipients [42]. Hurst et al. found reduced graft survival even if the patients with chronic obstructive air way disease were excluded [42]. These findings suggest that cigarette smoking has deleterious effect on graft survival irrespective of its effects on mortality or causing chronic obstructive airway disease. However, not all studies demonstrated deleterious effects of cigarette smoking on graft function. Our literature review revealed at least 2 studies which did not show any correlation between cigarette smoking and reduced graft survival $[45,46]$. Table 2 summarizes studies done on cigarette smoking and its effects on graft survival.

4.3. Cigarette Smoking and Patient Survival in Kidney Transplant Recipient. There are a number of studies that showed increased mortality in kidney transplant recipients due to cigarette smoking [29, 31, 33-35, 39, 42, 45, 48, 49]. Our review of literature showed two meta-analyses on recipient mortality. One meta-analysis, done in solid organ transplantation, showed shorter patient survival and higher odds of mortality in smokers [47]. In another meta-analysis from Iran [31] done in kidney transplant recipients only, the relative risk for death varied between 0.8 and 2.2. Increased mortality has been reported in heavy smokers. Cigarette smoking of more than 25 pack-years at time of transplantation was associated with increased mortality [33]. Luckily, the effect of cigarette smoking on mortality vanishes after 5 years of quitting signifying the importance of continuous efforts to counsel patients to quit cigarette smoking [33]. The effect of cigarette smoking on mortality may appear later in life. Cigarette smoking did not affect mortality during the first year; however, after 1 year, smoking leads to increased mortality [34]. Active smoking has been shown to reduce graft survival as compared to past smoking. However, both active and past smoking have been shown to increase mortality in the recipients [39]. Hurst et al. [42] found that, compared with never smokers, incident cigarette smoking after transplant was also associated with increased risk of death. Donor cigarette smoking is also an important factor in causing mortality along with recipient smoking. In fact, the two together may augment each other's effects. Smoking in combination with other factors leads to higher mortality [29]. History of current and previous smoking in recipients with malignancy is also associated with increased mortality [48]. Similarly, increasing age, diabetes, and hypertension in combination with smoking lead to increased mortality [49]. The effect of smoking on mortality has been enormous and it is considered to be equivalent to diabetes [34]. From this discussion, it emerges that both active and past cigarette smoking adversely affect recipient survival. The effect on mortality is more in heavy smoker. Smoking in combination with increasing age, diabetes, hypertension, and malignancy causes increased mortality. Therefore, all efforts should be done in convincing recipients to quit smoking. Table 3 summarizes studies done on implication of cigarette smoking on kidney transplant recipient survival.

4.4. Cigarette Smoking and Allograft Rejection. Many epidemiologic studies have shown late allograft rejection in kidney, heart, and bone marrow transplant in cigarette smokers $[36,41,50-55]$. The mechanism by which cigarette smoking causes rejection was studied in animal model by Wan et al. [56]. Costimulatory blockade by blocking CD154 induces indoleamine 2,3-dioxygenase activity in pancreatic allograft in mice. This in turn leads to increased survival of the graft. Wan et al. showed that second-hand smoking in mice suppressed mRNA and protein expression of indoleamine 2,3dioxygenase and shortens allograft survival in a cause-effect manner [56]. The author concluded that their finding was due to cigarette smoking related allograft rejection. Nogueira et al. compared live related kidney transplant recipients between smokers and never smokers [57]. They found that the risk of rejection on or before posttransplant day 10 was much higher (adjusted HR, 1.8; 95\% CI, 1.10-2.94; $P=0.02$ ) in smokers. These findings are not unanimous as there are other studies that did not show any associations. Sung et al. in their cohort did not find any relation between cigarette smoking and rejection [41]. No relation was found between smoking and rejection by Kheradmand and Shahbazian [38]. An open randomized trial is currently being conducted to determine the effectiveness of carbon monoxide-oximetry and anticigarette smoking counselling in a cohort of kidney transplant patients who smoke [58]. This randomized open label study will assess its effectiveness on cessation of cigarette smoking and will measure various outcomes including rejection. The study may give some insight about association of smoking with rejection.

4.5. Cigarette Smoking and Infections in Kidney Transplant Recipient. Cigarette smoking affects the function of white blood cells. Migration and chemotaxis of polymorph nuclear cells decrease in smokers when compared to nonsmokers $[59,60]$. Macrophages from smoker lungs have more potent inhibitory effects on lymphocytes resulting in reduced cellular immunity [61]. Cigarette smoking decreases various proinflammatory cytokines such as IL-1, IL-6, tumor necrosis factor $\alpha$, and IL-2 [62-65]. The effect of cigarette smoking on lymphocytes is confusing. There is increase in the ratio of CD4+ to CD8+ lymphocytes in light smokers. This was due to the increase in CD4+ cells in light to moderate 
TABLE 2: Summary of previous publications on implication of cigarette smoking on graft survival.

\begin{tabular}{llll}
\hline Number & Author & Journal/year & Finding \\
\hline
\end{tabular}

(1) Kasiske and Klinger $\quad J$ Am SocNephrol/2000

Smoking more than 25 pack-years at transplantation (compared to smoking less than 25 pack-years or never having smoked) was associated with a $30 \%$ higher risk of graft failure (relative risk 1.30; $95 \%$ confidence interval $[\mathrm{CI}], 1.04$ to $1.63 ; P=0.021$ ). Having quit smoking for more than 5 years before transplantation reduced the relative risk of graft failure by $34 \%$ (relative risk $0.66 ; 95 \% \mathrm{CI}, 0.52$ to $0.85 ; P, 0.001$ )

(1) Past history of smoking in recipient did not have any impact on graft survival

\begin{tabular}{ll} 
(2) Agarwal et al. [39] Am J Nephrol/2011 & $\begin{array}{c}\text { (2) Current smoking had higher risk for graft failure compared } \\
\text { to never smoking in renal transplant recipient (hazard ratio, } \\
\text { HR }=3.3,95 \% \text { CI } 1.5-7.1, P=0.002)\end{array}$ \\
\hline
\end{tabular}

\begin{tabular}{|c|c|c|c|}
\hline (3) & $\begin{array}{l}\text { Underwood et al. } \\
\qquad[29]\end{array}$ & Clin Transplant./2014 & Recipient smoking reduces graft survival $(\mathrm{HR}=1.74, P=0.05)$ \\
\hline (4) & Gombos et al. [40] & Transplant Proc. 2010 & $\begin{array}{l}\text { No difference in creatinine at } 3 \text { months, but creatinine at } 1 \text { year } \\
\text { was significantly higher in smokers }\end{array}$ \\
\hline (5) & Sung et al. [41] & Transplantation/2001 & $\begin{array}{l}\text { Patients who were smokers at the time of pretransplant } \\
\text { evaluation had kidney graft survival of } 84 \%, 65 \% \text {, and } 48 \% \text { at } 1 \text {, } \\
5 \text {, and } 10 \text { years, respectively, compared with graft survival in } \\
\text { nonsmokers of } 88 \%, 78 \% \text {, and } 62 \%(P=0.007) \text { Pretransplant } \\
\text { smoking adversely affected death-censored graft survival in } \\
\text { recipients of cadaveric }(P=0.02) \text { and of living donor kidneys } \\
(P=0.02) \text {. In a multivariate analysis, pretransplant smoking } \\
\text { was associated with a relative risk of } 2.3 \text { for graft loss }\end{array}$ \\
\hline
\end{tabular}

(1) Compared with never smokers, incident smoking after transplant was associated with increased risk of death-censored allograft loss (adjusted hazard ratio [AHR] 1.46 [95\% confidence interval $\{\mathrm{CI}\}: 1.19-1.79]$; $P<0.001)$

(6) Hurst et al. [42] Transplantation/2011

(2) In a sensitivity analysis excluding patients with history of chronic obstructive pulmonary disease, similar results were obtained with increased risk of death-censored allograft loss (AHR 1.43 [95\% CI: 1.16-1.76]; $P=0.001$ ) and death (AHR 2.26 [95\% CI: 1.91-2.66]; $P<0.001$ )

\begin{tabular}{|c|c|c|c|}
\hline (7) & Cosio et al. [34] & Clin Transplant./1999 & $\begin{array}{l}\text { Cox regression analysis showed significantly shorter graft } \\
\text { survival in smokers }(P=0.0005)\end{array}$ \\
\hline (8) & Matas et al. [43] & Ann Surg./2001 & $\begin{array}{l}\text { Pretransplant smoking was an important risk factor of a poorer } \\
\text { long-term graft survival among recipients with 1-year graft } \\
\text { survival }(\mathrm{RR}, 2.1)\end{array}$ \\
\hline (9) & Woo et al. [44] & J Nephrol/2002 & $\begin{array}{l}\text { Cox regression analysis showed that cigarette smoking was } \\
\text { associated with graft failure having relative risk of } 1.81\end{array}$ \\
\hline (10) & $\begin{array}{l}\text { Kheradmand and } \\
\text { Shahbazian [38] }\end{array}$ & Urol J/2005 & $\begin{array}{l}\text { Pretransplant smoking was significantly associated with reduced } \\
\text { overall graft survival }(P=0.01) \text {, but no correlation between } \\
\text { smoking cessation after transplantation with survival graft was } \\
\text { found }\end{array}$ \\
\hline (11) & Yavuz et al. [45] & Transplant Proc/2004 & $\begin{array}{l}\text { No significant relationship between pretransplant smoking and } \\
\text { educational status }(P=0.354) \text {; graft loss; and smoking } \\
(P=0.129) \text { was found }\end{array}$ \\
\hline (12) & $\begin{array}{l}\text { Mohamed Ali et al. } \\
\qquad[46]\end{array}$ & $\begin{array}{l}\text { Saudi J Kidney Dis } \\
\text { Transpl./2009 }\end{array}$ & $\begin{array}{l}\text { The mean graft survival in patients who were smokers at the } \\
\text { time of pretransplant evaluation was } 89.3 \% \text { compared with } \\
92.5 \% \text { in the nonsmokers }(P=0.347)\end{array}$ \\
\hline
\end{tabular}

smoker who smokes less than 50 packs per year [6668]. In contrast, there are a decrease CD4+ cells and an increase in CD8+ lymphocytes in heavy smokers (greater than 50 packs per year) [67]. Other studies have reported no difference in the CD4+ and CD8+ lymphocyte counts among moderate smokers [69]. Since $\mathrm{CD} 4^{+}$lymphocytes are important for B cell proliferation, decreased levels can potentially result in less antibodies production. Similarly, 
TABLE 3: Summary of studies on implications of cigarette smoking on kidney transplant recipient survival.

\begin{tabular}{|c|c|c|c|}
\hline Number & Author & Journal/year & Conclusion \\
\hline (1) & $\begin{array}{l}\text { Kasiske and Klinger } \\
\text { [37] }\end{array}$ & $\begin{array}{c}\text { J Am } \\
\text { SocNephrol/2000 }\end{array}$ & $\begin{array}{l}\text { The increase in graft failure was due to an increase in deaths (adjusted relative risk } \\
1.42 ; 95 \% \text { CI, } 1.08 \text { to } 1.87 ; P=0.012 \text { ) }\end{array}$ \\
\hline$(2)$ & Agarwal et al. [39] & Am J Nephrol/2011 & $\begin{array}{l}\text { Current smoking and past smoking in renal transplant recipient resulted in higher } \\
\text { risk for death than never smoking }(\mathrm{HR}=2.1,95 \% \mathrm{CI} 1.1-3.8, P=0.016 \text {, and } \\
\mathrm{HR}=2.4,95 \% \mathrm{CI} 1.4-4.0, P=0.001 \text {, resp.). }\end{array}$ \\
\hline (3) & $\begin{array}{l}\text { Underwood et al. } \\
\qquad[29]\end{array}$ & Clin Transplant./2014 & $\begin{array}{l}\text { Both donor and recipient smoking decreased recipient survival }(\mathrm{HR}=1.93 \\
P<0.01 \text { versus } \mathrm{HR}=1.74, P=0.048)\end{array}$ \\
\hline$(4)$ & Duerinckx et al. [47] & Transplantation/2016 & $\begin{array}{l}\text { Shorter patient survival time (OR } 0.59,95 \% \text { CI } 0.44-0.79 \text { ) and higher odds of } \\
\text { mortality (OR } 1.74,95 \% \text { CI } 1.21-2.48 \text { ) in solid organ transplantation }\end{array}$ \\
\hline (5) & $\begin{array}{l}\text { Opelz and Döhler } \\
\qquad[48]\end{array}$ & Transplantation/2016 & $\begin{array}{l}\text { Compared with patients who had never smoked }(n=31,462) \text {, patients who stopped } \\
\text { smoking before transplantation has increased chances of death }(\mathrm{HR}, 1.1 ; 95 \% \mathrm{CI} \text {, } \\
1.0-1.2 ; P<0.001) \text { and a similar risk of death-censored graft failure }(\mathrm{HR}, 1.0,95 \% \\
\text { CI, } 1.0-1.1 ; P=0.19) \text {, but a } 40 \% \text { increase in death from malignancy }(\mathrm{HR}, 1.4 ; 95 \% \\
\text { CI, } 1.2-1.7 ; P<0.001)\end{array}$ \\
\hline (6) & Hurst et al. [42] & Transplantation/2011 & $\begin{array}{l}\text { Compared with never smokers, incident smoking after transplant was associated } \\
\text { with increased risk death (AHR [adjusted hazard ratio] } 2.32 \text { [95\% CI: 1.98-2.72]; } \\
P<0.001 \text { ) }\end{array}$ \\
\hline (7) & Arend et al. [49] & $\begin{array}{c}\text { Nephrol Dial } \\
\text { Transplant/1997 }\end{array}$ & $\begin{array}{l}\text { Smoking was associated with increased mortality after }>1 \text { year posttransplantation } \\
\text { RR (95\% CI) } 2.2(1.4-3.7)\end{array}$ \\
\hline$(8)$ & Cosio et al. [34] & Clin Transplant./1999 & $\begin{array}{l}\text { By Cox regression, patient survival time was significantly shorter in diabetics } \\
(P<0.0001) \text {, smokers }(P=0.0005) \text {, and recipients older than } 40 \mathrm{yr}\end{array}$ \\
\hline (9) & Woo et al. [35] & $\begin{array}{c}\text { Journal of } \\
\text { Nephrol/2002 }\end{array}$ & Smoking was an independent risk factor for patient survival (hazard ratio, 1.81) \\
\hline (10) & Yavuz et al. [45] & Transplant Proc/2004 & $\begin{array}{l}\text { No significant relationship between pretransplant smoking and educational status } \\
(P=0.354) \text {; graft loss; and smoking }(P=0.129) \text { was found }\end{array}$ \\
\hline
\end{tabular}

increase in $\mathrm{CD}^{+}$cells has been associated with infection and malignancy [70]. Natural killer cells and immunoglobulin ( $\operatorname{IgA}, \operatorname{IgG}$, and $\operatorname{IgM}$ ) levels are also reduced in smokers, which will reduce immune threshold further [71-73]. Tobacco use is an independent predictor of all-cause and infection-related mortality in hemodialysis patients [74, 75]. Keeping these factors in mind, kidney transplant recipients with reduced immunity will be at more risk of developing infections.

Not surprisingly, the recipients are prone to multiple infections after transplantation. Legionnaires' disease is common in kidney transplant recipients causing community acquired pneumonia in 1-3\% [76] and smoking has been its independent risk factor [77]. The risk of Legionnaires' disease in the general population increases by $121 \%$ by cigarette smoking of 1 pack of cigarette daily [78]. We expect that this risk may be even more severe in kidney transplant recipients who have less immunity as compared to general population. Several studies in the general population have shown association of cigarette smoking with influenza infection [79-81]. Similar association was found between cigarette smoking and influenza in kidney transplant recipients [82]. Varicella infections are also common in kidney transplant recipients $[83,84]$ and it has been shown in studies involving the general population that smokers are at higher risk of contracting varicella pneumonitis resulting in admissions when compared to nonsmokers [85]. Population studies have shown that the risk of varicella pneumonitis increases by 15 folds in smokers [86]. We expect that this will hold true for kidney transplant recipients as well to have more varicella pneumonitis. Tuberculosis is also common in kidney transplant recipients $[87,88]$ and there is plenty of evidence in general population describing the association of cigarette smoking with tuberculosis [89-92]. Cigarette smoking in combination with BK virus increases risk of bladder cancers in renal transplant recipients [93]. Human papilloma virus is also associated with cigarette smoking. Minkoff et al. [94] reported higher baseline HPV16 and HPV18 DNA load in active smokers. The combination of cigarette smoking with high viral load of human papilloma virus (HPV) in kidney transplant recipients will not only increase the likelihood of infection but also may lead to development of HPV-related tumors.

There is plenty of evidence linking cigarette smoking with various infections in general population. However there is a paucity of good data to confirm this relationship in patients with kidney transplants. An ongoing open label randomized control trial in kidney transplant recipients is under way. Recipient will be followed up for 1 year to assess effectiveness of smoking cessation and the study will measure various variable including infections [58]. This study may provide more evidence for relationship of smoking with infection in the future.

4.6. Cigarette Smoking and Cancers in Kidney Transplant Recipient. Immunosuppression in kidney transplant recipients increases risk of cancer [95]. Squamous cell carcinoma is 20 times more common in kidney transplant recipient as 
compared to the general population [96]. Immunosuppression increases risk of cancer by two mechanisms. Immune surveillance for tumor antigen is reduced resulting in more opportunistic viral infections like cytomegalovirus, human papilloma virus, Epstein-Barr virus, and hepatitis B and C virus. These viruses in turn increase risk of malignancy. It is well known that cigarette smoking increases the risk of cancer in general population [97, 98]. Nonmelanoma skin cancers are one of the major causes of morbidity after organ transplantation [99]. Squamous cell carcinoma is the commonest nonmelanoma cancer of all the cutaneous malignancies $[99,100]$, with a $65-100$-fold increase of incidence in transplant recipients compared to the general population. Sun exposure, sensitivity to ultraviolet radiation, and cigarette smoking have been implicated as etiological factors in squamous cell carcinoma [101]. Human papilloma virus is another risk factor for squamous cell carcinoma and it has been found that active smokers have higher baseline HPV16 and HPV18 DNA load [94]. This can theoretically increase the risk of squamous cell carcinoma. However, in a metaanalysis [47], in solid organ transplantations, posttransplant cigarette smoking was positively correlated with nonskin malignancies (OR 2.58, 95\% CI 1.26-5.29). Lymphoproliferative disorders are also common in kidney transplant recipients [102]. Since cigarette smoking has been implicated in follicular lymphoma and Hodgkin's disease in the general population $[103,104]$, it is possible that it may play an important causative role in the transplant population as well. Human papilloma virus and cervical carcinoma are well documented in transplant recipients [105]. By extension, one can assume that cigarette smoking may have a more pathogenic role in causation of cervical carcinoma in transplant patients.

Kasiske and Klinger showed that cigarette smoking was a risk factor for invasive malignancies [37]. The relative risk increases from 0.97 to 1.99 with increasing number of packs of cigarettes. However, cigarette smoking had no statistically significant effect on cancers other than lung cancer [37]. Cigarette smoking cessation for more than 5 years before transplantation did not reduce the risk of cancer in this study. Nägele et al. [52] in a study done with heart transplant patients reported higher rate of malignancies (7/22 smokers developed cancer, as compared to 4 cancers in 62 nonsmokers, $P=0.0001)$. Increasing age, sun exposure, and cigarette smoking habits have been shown to increase risk of malignancy in various studies in kidney transplant recipients [106108]. Smoking not only has etiological role but also increases mortality in kidney transplant recipients with malignancy. The mortality risk from malignancy is $40 \%$ higher in those who continued cigarette smoking as compared to those who stopped cigarette smoking after transplantation [48]. Cigarette smoking and BK virus have been found as significant etiological factors for bladder tumors in kidney transplant recipients [93]. Bearing these evidences in mind, counselling for cigarette smoking cessation should be advocated to all recipients to reduce risk of long-term complications from malignancies.

\section{Effect of Kidney Transplantation on Cigarette Smoking Behavior}

Kidney transplantation provides an opportunity to both donors and recipients to quit cigarette smoking. Continuation of cigarette smoking causes fatal medical events in both donor and recipient. Kidney donors who are smokers are less likely to provide follow-up information requested by transplant centers [26]. Kidney transplantation is in fact an incentive for patients to stop cigarette smoking. Keles and his colleagues [30] reported that preoperative cigarette smoking status in live donors was $47 \%$. Postoperatively, it reduced significantly to $29 \%$. This could be because of predonation counselling. Other reasons for this could be frequent contacts of the donor in the donor clinic and resulting fear that continuation of cigarette smoking may affect the solitary kidney. Banas et al. [109] reported that $27.6 \%$ of smokers stopped cigarette smoking after kidney transplantation. The cessation of cigarette smoking was more prevalent in patients $<55$ years of age and females. The cessation of cigarette smoking after transplantation in kidney transplant recipients was greater in magnitude when compared to nicotine patch which was successful only $16.4 \%$ of the times at 12 months [109]. This was almost comparable with bupropion plus nicotine patch combination which results in cigarette smoking cessation in $35.5 \%$ at 12 months of therapy. Major medical events like myocardial infarction and stroke also increase health consciousness to quit cigarette smoking [52]. Getting a new kidney also transforms patient's life and may increase health consciousness of the recipient to quit cigarette smoking. Therefore, extensive counselling should be done with donors and recipients to encourage smoking cessation and this should be continued throughout subsequent clinic consultations.

\section{Recommendations}

Keeping in view the evidence available for hazards due to cigarette smoking, we highly recommend the following:

(1) A detailed history of smoking should be taken from both donor and recipient.

(2) Detailed explanation of possible hazards of cigarette smoking for the donor (perioperative complications, postoperative wound infection, and kidney dysfunction in future) should be done.

(3) Detailed explanation of possible hazards of cigarette smoking in recipient (increased cardiovascular mortality, decreased graft survival, decreased patient survival, possible rejection, infections, and malignancies) should be explained to the recipient.

(4) Those with history of cigarette smoking should be referred to dedicated smoking cessation clinic.

(5) Kidney donor should stop smoking at least 6 weeks before the surgery.

(6) Smoking cessation advice should be part of chronic kidney disease management before transplantation. 
(7) All efforts should be put in to ensure smoking cessation in kidney transplant recipients at least 6 weeks before surgery.

(8) Transplantation results in cigarette smoking cessation in both recipients and donors. However, to achieve $100 \%$ cessation, continuous education and counseling should be provided to both donor and recipient by transplant coordinator and transplant physicians

(9) Those who continue to smoke should have regular follow-up in smoking cessation clinic. Use of nicotine, bupropion, or varenicline can be used to quit cigarette smoking. Those using bupropion will need to monitor cyclosporine blood level.

\section{Conclusion}

Cigarette smoking has significant implications for both kidney donors and recipients. Cigarette smoking has been associated with perioperative complications, wound infections, and mortality in transplant recipients. Kidney donation increases health consciousness and decreases cigarette smoking in significant number of donors. However, more work is needed to assess the impact of cigarette smoking on renal function and mortality in kidney donors. Cigarette smoking causes increased cardiovascular events and leads to decreased patient and graft survival. Cigarette smoking may also be associated with rejections but this needs further studies for verifications. Additionally, cigarette smoking is associated with opportunistic infections and malignancies in kidney transplant recipients.

\section{Conflicts of Interest}

The authors declare that they have no conflicts of interest.

\section{References}

[1] WHO Global Health Observatory (GHO) data, "Prevalence of tobacco smoking," http://www.who.int/gho/tobacco/use/en/.

[2] World Health Organization, WHO Report on the Global Tobacco Epidemic, World Health Organization, Geneva, Switzerland, 2011.

[3] P. Jha, C. Ramasundarahettige, V. Landsman et al., "21st-century hazards of smoking and benefits of cessation in the United States," New England Journal of Medicine, vol. 368, no. 4, pp. 341350, 2013.

[4] U.S. Department of Health and Human Services, The Health Consequences of Smoking-50 Years of Progress: A Report of the Surgeon General, vol. 34, U.S. Department of Health and Human Services, Centers for Disease Control and Prevention, National Center for Chronic Disease Prevention and Health Promotion, Office on Smoking and Health, Atlanta, Ga, USA, 2015.

[5] G. Grassi, G. Seravalle, D. A. Calhoun et al., "Mechanisms responsible for sympathetic activation by cigarette smoking in humans," Circulation, vol. 90, no. 1, pp. 248-253, 1994.

[6] A. Groppelli, D. Giorgi, S. Omboni, G. Parati, and G. Manciat, "Persistent blood pressure increase induced by heavy smoking," Journal of Hypertension, vol. 10, no. 5, pp. 495-499, 1992.
[7] E. Ritz, U. Benck, E. Franek, C. Keller, M. Seyfarth, and J. Clorius, "Effects of smoking on renal hemodynamics in healthy volunteers and in patients with glomerular disease," Journal of the American Society of Nephrology, vol. 9, no. 10, pp. 1798-1804, 1998.

[8] H. R. Black, G. R. Zeevi, R. M. Silten, and G. J. Walker Smith, "Effect of heavy cigarette smoking on renal and myocardial arterioles," Nephron, vol. 34, no. 3, pp. 173-179, 1983.

[9] B. Oberai, C. W. M. Adams, and O. B. High, "Myocardial and renal arteriolar thickening in cigarette smokers," Atherosclerosis, vol. 52, no. 2, pp. 185-190, 1984.

[10] L. G. Dales, G. D. Friedman, A. B. Siegelaub, C. C. Seltzer, and H. K. Ury, "Cigarette smoking habits and urine characteristics: urinalysis abnormalities are more common is smokers, but the reasons are unclear.," Nephron, vol. 20, no. 3, pp. 167-170, 1978.

[11] J. Mulder, S. J. Pinto-Sietsma, and G. F. Diercks, "Smoking behavior and urinary albumin excretion (UAE) in general population," Journal of American Society of Nephrology, vol. 10, Article ID 175A, 1999.

[12] H. P. Chase, S. K. Garg, G. Marshall et al., "Cigarette smoking increases the risk of albuminuria among subjects with type i diabetes," JAMA: The Journal of the American Medical Association, vol. 265, no. 5, pp. 614-617, 1991.

[13] B. Stegmayr and F. Lithner, "Tobacco and end stage diabetic nephropathy," British Medical Journal (Clinical research ed.), vol. 295, no. 6598, pp. 581-582, 1987.

[14] G. Biesenbach, O. Janko, and J. Zazgornik, "Similar rate of progression in the predialysis phase in type I and type II diabetes mellitus," Nephrology Dialysis Transplantation, vol. 9, no. 8, pp. 1097-1102, 1994.

[15] M. M. Ward and S. Studenski, "Clinical prognostic factors in lupus nephritis: the importance of hypertension and smoking," Archives of Internal Medicine, vol. 152, no. 10, pp. 2082-2088, 1992.

[16] S. R. Orth, A. Stockmann, C. Conradt et al., "Smoking as a risk factor for end-stage renal failure in men with primary renal disease," Kidney International, vol. 54, no. 3, pp. 926-931, 1998.

[17] A. C. Pearce and R. M. Jones, "Smoking and anesthesia: preoperative abstinence and perioperative morbidity," Anesthesiology, vol. 61, no. 5, pp. 576-584, 1984.

[18] J. R. Kambam, L. H. Chen, and S. A. Hyman, "Effect of short-term smoking halt on carboxyhemoglobin levels and P50 values," Anesthesia and Analgesia, vol. 65, no. 11, pp. 1186-1188, 1986.

[19] J. R. Smith and S. A. Landaw, "Smokers' polycythemia," New England Journal of Medicine, vol. 298, no. 1, pp. 6-10, 1978.

[20] A. M. Arozullah, S. F. Khuri, W. G. Henderson, and J. Daley, "Development and validation of a multifactorial risk index for predicting postoperative pneumonia after major noncardiac surgery," Annals of Internal Medicine, vol. 135, no. 10, pp. 847857, 2001.

[21] A. M. Møller, N. Villebro, T. Pedersen, and H. Tønnesen, "Effect of preoperative smoking intervention on postoperative complications: a randomised clinical trial," The Lancet, vol. 359, no. 9301, pp. 114-117, 2002.

[22] A. P. Monaco and P. J. Morris, "Care of the live kidney donor: consensus on the ultimate gift," Transplantation, vol. 79, no. 6, p. S51, 2005.

[23] D. L. Segev, A. D. Muzaale, B. S. Caffo et al., "Perioperative mortality and long-term survival following live kidney donation," JAMA - Journal of the American Medical Association, vol. 303, no. 10, pp. 959-966, 2010. 
[24] S. Patel, J. Cassuto, M. Orloff et al., "Minimizing morbidity of organ donation: analysis of factors for perioperative complications after living-donor nephrectomy in the united states," Transplantation, vol. 85, no. 4, pp. 561-565, 2008.

[25] G. Mjøen, O. Øyen, H. Holdaas, K. Midtvedt, and P.-D. Line, "Morbidity and mortality in 1022 consecutive living donor nephrectomies: benefits of a living donor registry," Transplantation, vol. 88, no. 11, pp. 1273-1279, 2009.

[26] E. S. Ommen, D. LaPointe Rudow, R. K. Medapalli, B. Schröppel, and B. Murphy, "When good intentions are not enough: obtaining follow-up data in living kidney donors," American Journal of Transplantation, vol. 11, no. 12, pp. 25752581, 2011.

[27] R. Robert, J. Guilhot, M. Pinsard et al., "A pair analysis of the delayed graft function in kidney recipient: the critical role of the donor," Journal of Critical Care, vol. 25, no. 4, pp. 582-590, 2010.

[28] J. Heldt, R. Torrey, D. Han et al., "Donor smoking negatively affects donor and recipient renal function following living donor nephrectomy," Advances in Urology, Article ID 929263, 2011.

[29] P. W. Underwood, K. H. Sheetz, D. C. Cron, M. N. Terjimanian, M. J. Englesbe, and S. A. Waits, "Cigarette smoking in living kidney donors: donor and recipient outcomes," Clinical Transplantation, vol. 28, no. 4, pp. 419-422, 2014.

[30] M. Keles, U. Avsar, Z. Avsar et al., "Effect of kidney transplantation on smoking habits of kidney donors," Transplantation Proceedings, vol. 47, no. 5, pp. 1302-1305, 2015.

[31] M. H. Nourbala, E. Nemati, Z. Rostami, and B. Einollahi, "Impact of cigarette smoking on kidney transplant recipients a systematic review," Iranian Journal of Kidney Diseases, vol. 5, no. 3, pp. 141-148, 2011.

[32] S.-J. Lin, J. K. Koford, B. C. Baird et al., "Effect of donors' intravenous drug use, cigarette smoking, and alcohol dependence on kidney transplant outcome," Transplantation, vol. 80, no. 4, pp. 482-486, 2005.

[33] B. L. Kasiske, H. A. Chakkera, and J. Roel, "Explained and unexplained ischemic heart disease risk after renal transplantation," Journal of the American Society of Nephrology, vol. 11, no. 9, pp. 1735-1743, 2000.

[34] F. G. Cosio, M. E. Falkenhain, T. E. Pesavento et al., "Patient survival after renal transplantation: II. the impact of smoking," Clinical Transplantation, vol. 13, no. 4, pp. 336-341, 1999.

[35] Y. M. Woo, D. McLean, D. D. Kavanagh et al., "The influence of pre-operative electrocardiographic abnormalities and cardiovascular risk factors on patient and graft survival following renal transplantation," Journal of Nephrology, vol. 15, pp. 380386, 2002.

[36] C. Ponticelli, M. Villa, B. Cesana, G. Montagnino, and A. Tarantino, "Risk factors for late kidney allograft failure," Kidney International, vol. 62, no. 5, pp. 1848-1854, 2002.

[37] B. L. Kasiske and D. Klinger, "Cigarette smoking in renal transplant recipients," Journal of the American Society of Nephrology, vol. 11, pp. 753-759, 2000.

[38] A. Kheradmand and H. Shahbazian, "The role of pretransplant smoking on allograft survival in kidney recipients," Urology Journal, vol. 2, no. 1, pp. 36-39, 2005.

[39] P. K. Agarwal, M. E. Hellemons, D. M. Zelle et al., "Smoking is a risk factor for graft failure and mortality after renal transplantation," American Journal of Nephrology, vol. 34, no. 1, pp. 26-31, 2011.
[40] P. Gombos, R. M. Langer, R. Korbely et al., "Smoking following renal transplantation in Hungary and its possible deleterious effect on renal graft function," Transplantation Proceedings, vol. 42, no. 6, pp. 2357-2359, 2010.

[41] R. S. Sung, M. Althoen, T. A. Howell, A. O. Ojo, and R. M. Merion, "Excess risk of renal allograft loss associated with cigarette smoking," Transplantation, vol. 71, no. 12, pp. 1752$1757,2001$.

[42] F. P. Hurst, M. Altieri, P. P. Patel et al., "Effect of smoking on kidney transplant outcomes: analysis of the United States renal data system," Transplantation, vol. 92, no. 10, pp. 1101-1107, 2011.

[43] A. J. Matas, W. D. Payne, D. E. R. Sutherland et al., "2,500 Living donor kidney transplants: a single-center experience," Annals of Surgery, vol. 234, no. 2, pp. 149-164, 2001.

[44] Y. M. Woo, D. McLean, D. Kavanagh et al., "The influence of preoperative electrocardiographic abnormalities and cardiovascular risk factors on patient and graft survival following renal transplantation," Journal of Nephrology, vol. 15, pp. 380-386, 2002.

[45] A. Yavuz, M. Tuncer, A. Gürkan et al., "Cigarette smoking in renal transplant recipients," Transplantation Proceedings, vol.36, no. 1, pp. 108-110, 2004.

[46] A. A. Mohamed Ali, G. Abraham, M. Mathew et al., "Can serial eGFR, body mass index and smoking predict renal allograft survival in South Asian patients," Saudi Journal of Kidney Diseases and Transplantation, vol. 20, no. 6, pp. 984-990, 2009.

[47] N. Duerinckx, H. Burkhalter, S. J. Engberg et al., "Correlates and outcomes of posttransplant smoking in solid organ transplant recipients: a systematic literature review and meta-analysis," Transplantation, vol. 100, no. 11, pp. 2252-2263, 2016.

[48] G. Opelz and B. Döhler, "Influence of current and previous smoking on cancer and mortality after kidney transplantation," Transplantation, vol. 100, no. 1, pp. 227-232, 2016.

[49] S. M. Arend, M. J. K. Mallat, R. J. W. Westendorp, F. J. Van Der Woude, and L. A. Van Es, "Patient survival after renal transplantation; more than 25 years follow-up," Nephrology Dialysis Transplantation, vol. 12, no. 8, pp. 1672-1679, 1997.

[50] S. A. Joosten, Y. W. J. Sijpkens, C. Van Kooten, and L. C. Paul, "Chronic renal allograft rejection: pathophysiologic considerations," Kidney International, vol. 68, no. 1, pp. 1-13, 2005.

[51] H. Cardinal, M.-J. Hébert, E. Rahme et al., "Modifiable factors predicting patient survival in elderly kidney transplant recipients," Kidney International, vol. 68, no. 1, pp. 345-351, 2005.

[52] H. Nägele, P. Kalmár, W. Rödiger, and H. M. Stubbe, "Smoking after heart transplantation: an underestimated hazard?" European Journal of Cardio-thoracic Surgery, vol. 12, no. 1, pp. 70-74, 1997.

[53] N. Zitt, B. Kollerits, U. Neyer et al., "Cigarette smoking and chronic allograft nephropathy," Nephrology Dialysis Transplantation, vol. 22, no. 10, pp. 3034-3039, 2007.

[54] M. R. Mehra, P. A. Uber, A. Prasad, R. L. Scott, and M. H. Park, "Recrudescent tobacco exposure following heart transplantation: clinical profiles and relationship with athero-thrombosis risk markers," American Journal of Transplantation, vol. 5, no. 5, pp. 1137-1140, 2005.

[55] G. Chang, E. J. Orav, T. McNamara, M.-Y. Tong, and J. H. Antin, "Depression, cigarette smoking, and hematopoietic stem cell transplantation outcome," Cancer, vol. 101, no. 4, pp. 782-789, 2004.

[56] F. Wan, H. Dai, S. Zhang, Y. Moore, N. Wan, and Z. Dai, "Cigarette smoke exposure hinders long-term allograft survival by suppressing indoleamine 2, 3-dioxygenase expression," 
American Journal of Transplantation, vol. 12, no. 3, pp. 610-619, 2012.

[57] J. M. Nogueira, A. Haririan, S. C. Jacobs, M. Cooper, and M. R. Weir, "Cigarette smoking, kidney function, and mortality after live donor kidney transplant," American Journal of Kidney Diseases, vol. 55, no. 5, pp. 907-915, 2010.

[58] S. Pita-Fernández, R. Seijo-Bestilleiro, S. Pértega-Díaz et al., "A randomized clinical trial to determine the effectiveness of COoximetry and anti-smoking brief advice in a cohort of kidney transplant patients who smoke: study protocol for a randomized controlled trial," Trials, vol. 17, no. 1, article 174, 2016.

[59] G. L. Fisher, K. L. McNeill, G. L. Finch, F. D. Wilson, and D. W. Golde, "Functional evaluation of lung macrophages from cigarette smokers and nonsmokers," RES Journal of the Reticuloendothelial Society, vol. 32, no. 4, pp. 311-321, 1982.

[60] R. C. Noble and B. B. Penny, "Comparison of leukocyte count and function in smoking and nonsmoking young men," Infection and Immunity, vol. 12, no. 3, pp. 550-555, 1975.

[61] P. G. Holt, "Immune and inflammatory function in cigarette smokers," Thorax, vol. 42, no. 4, pp. 241-249, 1987.

[62] H. L. Twigg, D. M. Soliman, and B. A. Spain, "Impaired alveolar macrophage accessory cell function and reduced incidence of lymphocytic alveolitis in HIV-infected patients who smoke," AIDS, vol. 8, no. 5, pp. 611-618, 1994.

[63] M. D. Wewers, P. T. Diaz, M. E. Wewers, M. P. Lowe, H. N. Nagaraja, and T. L. Clanton, "Cigarette smoking in HIV infection induces a suppressrive inflammatory environment in the lung," American Journal of Respiratory and Critical Care Medicine, vol. 158, no. 5 I, pp. 1543-1549, 1998.

[64] Y. Ouyang, N. Virasch, P. Hao et al., "Suppression of human IL-1 $\beta$, IL- 2 , IFN- $\gamma$, and TNF- $\alpha$ production by cigarette smoke extracts," Journal of Allergy and Clinical Immunology, vol. 106, no. 2, pp. 280-287, 2000.

[65] E. Hagiwara, K.-I. Takahashi, T. Okubo et al., "Cigarette smoking depletes cells spontaneously secreting Th1 cytokines in the human airway," Cytokine, vol. 14, no. 2, pp. 121-126, 2001.

[66] D. A. Hughes, P. L. Haslam, P. J. Townsend, and M. TurnerWarwick, "Numerical and functional alterations in circulatory lymphocytes in cigarette smokers," Clinical and Experimental Immunology, vol. 61, no. 2, pp. 459-466, 1985.

[67] L. C. Ginns, P. D. Goldenheim, and L. G. Miller, “T-lymphocyte subsets in smoking and lung cancer: analysis of monoclonal antibodies and flow cytometry," American Review of Respiratory Disease, vol. 126, no. 2, pp. 265-269, 1982.

[68] L. G. Miller, G. Goldstein, M. Murphy, and L. C. Ginns, "Reversible alterations in immunoregulatory T cells in smoking. analysis by monoclonal antibodies and flow cytometry," Chest, vol. 82, no. 5, pp. 526-529, 1982.

[69] P. Hersey, D. Prendergast, and A. Edwards, "Effects of cigarette smoking on the immune system: follow-up studies in normal subjects after cessation of smoking," Medical Journal of Australia, vol. 2, no. 9, pp. 425-429, 1983.

[70] U. Costabel, K. J. Bross, C. Reuter, K. H. Rühle, and H. Matthys, "Alterations in immunoregulatory T-cell subsets in cigarette smokers: a phenotypic analysis of bronchoalveolar and blood lymphocytes," Chest, vol. 90, no. 1, pp. 39-44, 1986.

[71] A. Gulsvik and M. K. Fagerhol, "Smoking and immunoglobulin levels," The Lancet, vol. 313, article 8113, p. 449, 1979.

[72] J. W. Gerrard, D. C. Heiner, C. G. Ko, J. Mink, A. Meyers, and J. A. Dosman, "Immunoglobulin levels in smokers and nonsmokers," Annals of Allergy, vol. 44, no. 5, pp. 261-262, 1980.
[73] P. Andersen, O. F. Pedersen, B. Bach, and G. J. Bonde, "Serum antibodies and immunoglobulins in smokers and nonsmokers," Clinical and Experimental Immunology, vol. 47, pp. 467-473, 1982.

[74] M. Wagner, D. Ansell, D. M. Kent et al., "Predicting mortality in incident dialysis patients: an analysis of the United Kingdom renal registry," American Journal of Kidney Diseases, vol. 57, no. 6, pp. 894-902, 2011.

[75] F. R. Mc Causland, S. M. Brunelli, and S. S. Waikar, "Association of smoking with cardiovascular and infection-related morbidity and mortality in chronic hemodialysis," Clinical Journal of the American Society of Nephrology, vol. 7, no. 11, pp. 1827-1835, 2012.

[76] B. D. Kirby, K. M. Snyder, R. D. Meyer, and S. M. Finegold, "Legionnaires disease: report of 65 nosocomially acquired cases and a review of the literature," Medicine (Baltimore), vol. 59, p. 188,1980

[77] B. N. Doebbeling and R. P. Wenzel, "The epidemiology of Legionella Pneumophila infections," Seminars in Respiratory Infections, vol. 2, no. 4, pp. 206-221, 1987.

[78] W. L. Straus, J. F. Plouffe, T. M. File Jr. et al., “Ohio Legionnaires Disease Group, Risk factors for domestic acquisition of legionnaires disease," Archives of Internal Medicine, vol. 156, no. 15, pp. 1685-1692, 1996.

[79] J. F. Finklea, S. H. Sandifer, and D. D. Smith, "Cigarette smoking and epidemic influenza," American Journal of Epidemiology, vol. 90, no. 5, pp. 390-399, 1969.

[80] J. D. Kark and M. Lebiush, "Smoking and epidemic influenzalike illness in female military recruits: a brief survey," American Journal of Public Health, vol. 71, no. 5, pp. 530-532, 1981.

[81] J. D. Kark, M. Lebiush, and L. Rannon, "Cigarette smoking as a risk factor for epidemic A(H1N1) influenza in young men," New England Journal of Medicine, vol. 307, no. 17, pp. 1042-1046, 1982.

[82] J. A. Sparks, D. C. Brennan, and S. J. Lawrence, "Smoking association with influenza infection in renal transplant recipients," Transplant Infectious Disease, vol. 16, no. 1, pp. 153-157, 2014.

[83] Z. Mustapic, N. Basic-Jukic, P. Kes et al., "Varicella zoster infection in renal transplant recipients: prevalence, complications and outcome," Kidney and Blood Pressure Research, vol. 34, no. 6, pp. 382-386, 2011.

[84] S. A. Pergam and A. P. Limaye, "Varicella zoster virus (VZV) in solid organ transplant recipients," American Journal of Transplantation, vol. 9, no. 4, pp. S108-S115, 2009.

[85] M. E. Ellis, K. R. Neal, and A. K. Webb, "Is smoking a risk factor for pneumonia in adults with chickenpox?" British Medical Journal, BMJ, vol. 294, no. 6578, pp. 1002-1002, 1987.

[86] M. L. Grayson and H. Newton-John, "Smoking and varicella pneumonia," Journal of Infection, vol. 16, no. 3, p. 312, 1988.

[87] E. Canet, J. Dantal, G. Blancho, M. Hourmant, and S. Coupel, "Tuberculosis following kidney transplantation: clinical features and outcome. A French multicentre experience in the last 20 years," Nephrology Dialysis Transplantation, vol. 26, no. 11, pp. 3773-3778, 2011.

[88] A. K. Subramanian and M. I. Morris, "Mycobacterium tuberculosis infections in solid organ transplantation," American Journal of Transplantation, vol. 13, no. 4, pp. 68-76, 2013.

[89] G.-P. Yu, C.-C. Hsieht, and J. Peng, "Risk factors associated with the prevalence of pulmonary tuberculosis among sanitary workers in shanghai," Tubercle, vol. 69, no. 2, pp. 105-112, 1988.

[90] S. E. Buskin, J. L. Gale, N. S. Weiss, and C. M. Nolan, "Tuberculosis risk factors in adults in King County, Washington, 1988 
through 1990," American Journal of Public Health, vol. 84, no. 11, pp. 1750-1756, 1994.

[91] J. Alcaide, M. N. Altet, P. Plans et al., "Cigarette smoking as a risk factor for tuberculosis in young adults: a case-control study," Tubercle and Lung Disease, vol. 77, no. 2, pp. 112-116, 1996.

[92] V. Gajalakshmi, R. Peto, T. S. Kanaka, and P. Jha, "Smoking and mortality from tuberculosis and other diseases in India: retrospective study of 43000 adult male deaths and 35000 controls," Lancet, vol. 362, no. 9383, pp. 507-515, 2003.

[93] S. Liu, M. R. Chaudhry, A. A. Berrebi et al., "Polyomavirus replication and smoking are independent risk factors for bladder cancer after renal transplantation," Transplantation, 2016.

[94] H. Minkoff, J. G. Feldman, H. D. Strickler et al., "Relationship between smoking and human papillomavirus infections in HIV-infected and -uninfected women," Journal of Infectious Diseases, vol. 189, no. 10, pp. 1821-1828, 2004.

[95] O. M. Martinez and F. R. De Gruijl, "Molecular and immunologic mechanisms of cancer pathogenesis in solid organ transplant recipients," American Journal of Transplantation, vol. 8, no. 11, pp. 2205-2211, 2008.

[96] C. M. Vajdic, M. T. van Leeuwen, S. P. McDonald et al., "Increased incidence of squamous cell carcinoma of eye after kidney transplantation," Journal of the National Cancer Institute, vol. 99, no. 17, pp. 1340-1342, 2007.

[97] C. E. Bartecchi, T. D. MacKenzie, and R. W. Schrier, "The human costs of tobacco use," New England Journal of Medicine, vol. 330, no. 13, pp. 907-912, 1994.

[98] T. D. MacKenzie, C. E. Bartecchi, and R. W. Schrier, "The human costs of tobacco use (second of two parts)," New England Journal of Medicine, vol. 330, no. 14, pp. 975-980, 1994.

[99] J. Adami, H. Gäbel, B. Lindelöf et al., "Cancer risk following organ transplantation: a nationwide cohort study in Sweden," The British Journal of Cancer, vol. 89, no. 7, pp. 1221-1227, 2003.

[100] E. K. Geissler, "Skin cancer in solid organ transplant recipients: are mTOR inhibitors a game changer?" Transplantation Research, vol. 4, no. 1, article 1, 2015.

[101] M. M. Madeleine, J. J. Carter, L. G. Johnson et al., "Risk of squamous cell skin cancer after organ transplant associated with antibodies to cutaneous papillomaviruses, polyomaviruses, and TMC6/8 (EVER1/2) variants," Cancer Medicine, vol. 3, no. 5, pp. 1440-1447, 2014.

[102] W. D. Bates, D. W. R. Gray, M. A. Dada et al., "Lymphoproliferative disorders in Oxford renal transplant recipients," Journal of Clinical Pathology, vol. 56, no. 6, pp. 439-446, 2003.

[103] L. M. Morton, P. Hartge, T. R. Holford et al., "Cigarette smoking and risk of non-Hodgkin lymphoma: a pooled analysis from the International Lymphoma Epidemiology Consortium (InterLymph)," Cancer Epidemiology Biomarkers and Prevention, vol. 14, no. 4, pp. 925-933, 2005.

[104] H. Hjalgrim, K. Ekström-Smedby, K. Rostgaard et al., "Cigarette smoking and risk of hodgkin lymphoma: a population-based case-control study," Cancer Epidemiology Biomarkers and Prevention, vol. 16, no. 8, pp. 1561-1566, 2007.

[105] M. Veroux, D. Corona, G. Scalia et al., "Surveillance of human papilloma virus infection and cervical cancer in kidney transplant recipients: preliminary data," Transplantation Proceedings, vol. 41, no. 4, pp. 1191-1194, 2009.

[106] R. Marcn, "Immunosuppressive drugs in kidney transplantation: impact on patient survival, and incidence of cardiovascular disease, malignancy and infection," Drugs, vol. 69, no. 16, pp. 2227-2243, 2009.
[107] J. Dantal and E. Pohanka, "Malignancies in renal transplantation: an unmet medical need," Nephrology Dialysis Transplantation, vol. 22, supplement 1, pp. i4-i10, 2007.

[108] E. Danpanich and B. L. Kasiske, "Risk factors for cancer in renal transplant recipients," Transplantation, vol. 68, no. 12, pp. 18591864, 1999.

[109] M. C. Banas, B. Banas, J. Wolf et al., "Smoking behaviour of patients before and after renal transplantation," Nephrology Dialysis Transplantation, vol. 23, no. 4, pp. 1442-1446, 2008. 


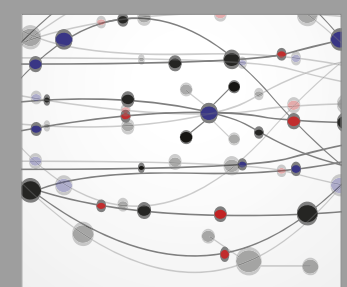

The Scientific World Journal
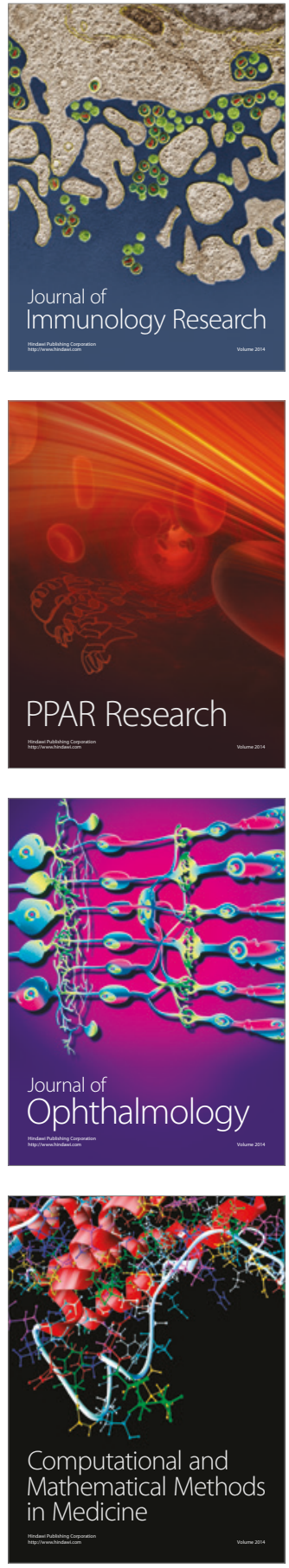

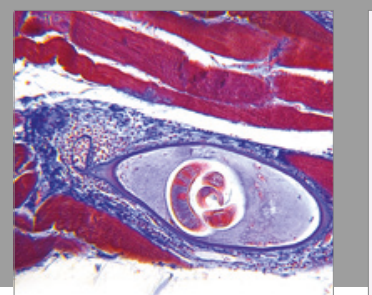

Gastroenterology Research and Practice
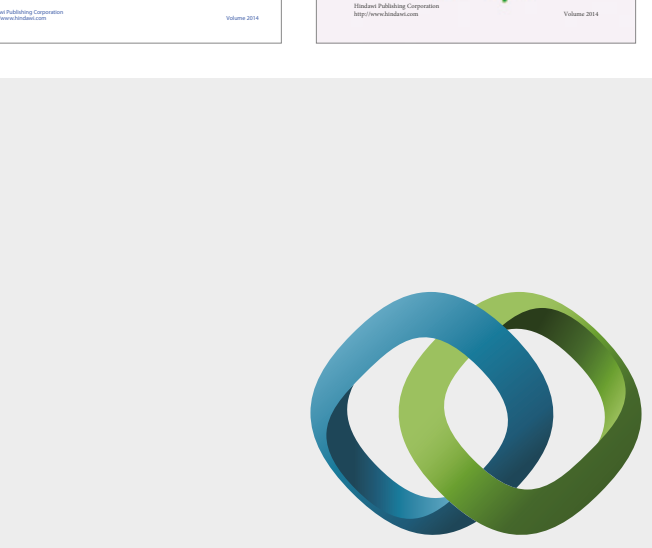

\section{Hindawi}

Submit your manuscripts at

https://www.hindawi.com
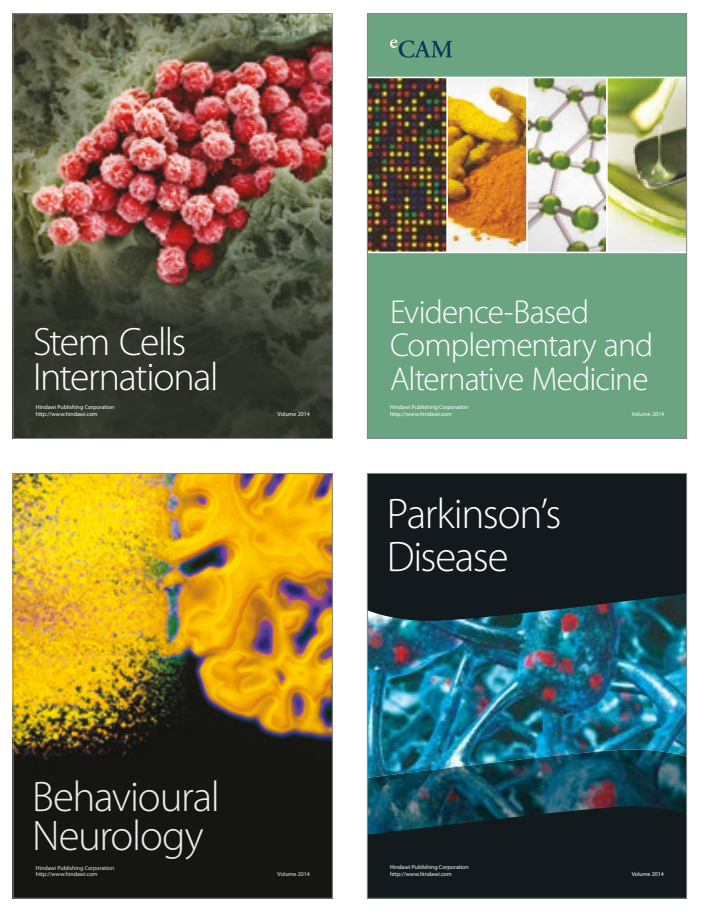
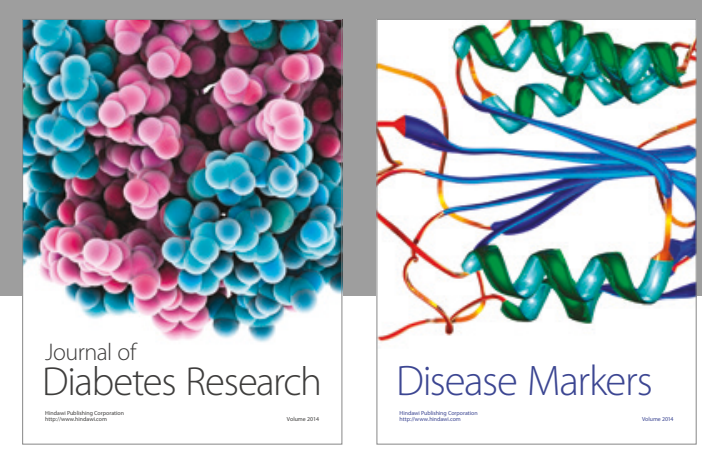

Disease Markers
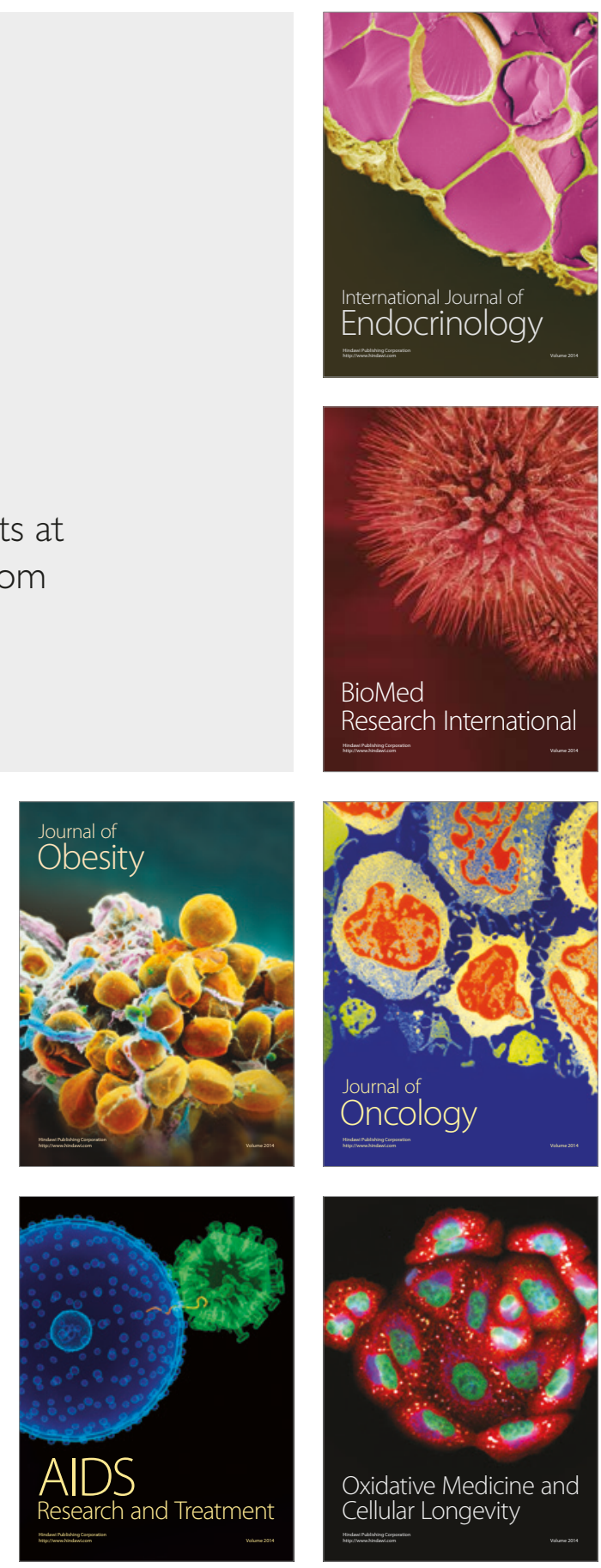